\title{
Complex karyotype in myelodysplastic syndromes: Diagnostic procedure and prognostic susceptibility
}

\author{
Mohammad Shahjahani, ${ }^{1}$ Elham Homaei Hadad, ${ }^{1}$ Shirin Azizidoost, ${ }^{1}$ Kowsar Chenani Nezhad, ${ }^{2}$ \\ Saeid Shahrabi ${ }^{3}$
}

${ }^{1}$ Thalassemia and Hemoglobinopathy Research Center, Research Institute of Health, Ahvaz Jundishapur University of Medical Sciences, Ahvaz; ${ }^{2}$ Noorgene genetic and clinical lab, Ahvaz, Iran; ${ }^{3}$ Thalassemia \& Hemoglobinopathy Research center, research institute of Health, Ahvaz, Jundishapur University of Medical Sciences, Ahvaz, Iran

\begin{abstract}
Complex karyotype (CK) is a poor prognosis factor in hematological malignancies. Studies have shown that the presence of CK in myelodysplastic syndrome (MDS) can be associated with MDS progression to acute myeloid leukemia. The goal of this review was to examine the relationship between different types of CK with MDS, as well as its possible role in the deterioration and progression of MDS to leukemia. The content used in this paper has been obtained by a PubMed and Google Scholar search of English language papers (1975-2018) using the terms complex karyotype and myelodysplastic syndromes. A single independent abnormality can be associated with a good prognosis. However, the coexistence of a series of abnormalities can lead to CK, which is associated with the deterioration of MDS and its progression to leukemia. Therefore, CK may be referred to as a prognostic factor in MDS. The detection of independent cytogenetic disorders that altogether can result in CK could be used as a prognostic model for laboratory and clinical use.
\end{abstract} Correspondence: Saeid Shahrabi, Department of Biochemistry and
Hematology, Faculty of Medicine, Semnan University of Medical
Sciences, Semnan, Iran. E-mail: sshahrabi45@yahoo.com

Key words: Myelodysplastic syndrome; diagnosis; complex karyotype.

Acknowledgments: we wish to thank all our colleagues at Noorgene Genetic and Clinical Laboratory, Ahvaz, Iran.

Contributions: SSh conceived the manuscript and revised it; MSh, EH, $\mathrm{ShA}$ and $\mathrm{KCh}$ wrote the manuscript and prepared the Tables.

Conflict of interest: the authors declare no conflict of interest.

Received for publication: 6 August 2018.

Revision received: 4 October 2018.

Accepted for publication: 3 January 2019.

This work is licensed under a Creative Commons Attribution NonCommercial 4.0 License (CC BY-NC 4.0).

(C) Copyright M. Shahjahani, et al., 2019

Licensee PAGEPress, Italy

Oncology Reviews 2019; 13:389

doi:10.4081/oncol.2019.389

\section{Introduction}

Complex karyotype (CK) is a classification of cytogenetic risks of hematologic malignancies associated with a poor prognosis, ${ }^{1}$ which has important applications in the diagnosis and prognosis of patients with hematological malignancies, including myelodysplastic syndrome (MDS), acute myeloid leukemia (AML), B-cell lymphoblastic leukemia/lymphoma (B-ALL), chronic myeloid leukemia (CML), chronic lymphocytic leukemia/small lymphocytic leukemia (CLL/SLL), and plasma cell myeloma (PCM). ${ }^{1-3}$ There is no clear definition of $\mathrm{CK}$ for various types of hematologic malignancies. $\geq 3$ independent cytogenetic abnormalities in most studies is considered as CK, but in Medical Research Council Acute Myeloid Leukemia 10 trial (MRC AML10), $\geq 5$ independent cytogenetic abnormalities are deemed as CK. ${ }^{4}$ Haase et al. demonstrated that the increase in chromosomal abnormalities can be associated with reduced survival rates of MDS patients. ${ }^{5}$ In this respect, there are a number of complementary techniques to investigate important chromosomal events involved in the progression of treatmentrelated secondary myelodysplastic syndrome (t-MDS). ${ }^{6}$ For example, spectral karyotyping (SKY), a laboratory technique based on hybridization of 24 fluorescently labeled chromosome painting probes, as well as fluorescence in situ hybridization (FISH), and conventional cytogenetics are techniques used for analysis of $\mathrm{CK}$ and t-MDS. 6,7

\section{Complex karyotype as a prognosis predictor in myelodysplastic syndrome}

MDS is an abnormality of bone marrow (BM) stem cells associated with monocytopenia, bicytopenies, or pancytopenia..$^{5,8}$ Recent studies indicate that up to $30 \%$ of de novo MDS cases are associated with $\mathrm{CK}$ in initial cytogenetic evaluation. ${ }^{9}$ On the other hand, studies have indicated more frequent chromosomal abnormalities in t-MDS than de novo MDS. -7 (14\%), -5q (28\%), $-5(11 \%)$, der (21q), +8, -7q, der (12q), t (1;7), -12, der (17q), der $(3 q)$, der $(3 q)$, and -18 are among the most common chromosomal abnormalities in t-MDS. ${ }^{10}$ International Prognostic Scoring System (IPSS) classifies MDS cytogenetic results into four groups of low, int-1, int-2, and high according to the risk of death or transformation to AML. Sconocchia et al. state that chromosome 7 anomalies and complex karyotype are placed on a high-risk class. ${ }^{11}$ MDS is often transformed to AML, but it can also transform to other leukemia, including acute lymphocytic leukemia (ALL). ${ }^{12}$ Each chromosomal abnormality in MDS is shown to be associated with a different prognosis; for example, 
$\operatorname{del}(5 q)$, del $(7 q) /-5 /-7$, and +8 are considered to be associated with favorable, unfavorable, and indeterminate prognosis, respectively. ${ }^{13}$ On the other hand, has been observed that the higher numbers of the independent cytogenetic abnormalities in MDS patients (usually $\leq 3$ independent cytogenetic abnormalities), the poorer prognosis of the MDS. ${ }^{14}$ As a result, assessment of CK in MDS can be useful in determining prognosis and finding new therapies (Table 1).

\section{TP53 mutations and del (5q) with complex karyotype}

\section{TP53 mutations}

TP53 is a tumor suppressor gene (TSGs), the mutation of which can be associated with increased proliferation and survival of tumor cells. ${ }^{15}$ In this regard, Wang et al. in their recent study have shown that most MDS patients harbor TP53 mutation and therefore have a poor prognosis. ${ }^{16}$ Moreover, $\operatorname{del}(5 q) /-5>\operatorname{del}(7 q)$ $/-7<$ del $(17 \mathrm{p}) /-17$ is observed in MDS patients with CK. No relationship has been found between del (7q)/-7 and del (5q)/-5 with TP53; ${ }^{16-18}$ on the other hand, since TP53 gene is located on $17 \mathrm{p}$, coexistence of mutation in $17 \mathrm{p}$ region and deletion of chromosome 17 can involve both TP53 alleles and result in deactivation of both copies of TP53 gene in a majority of cases. Therefore, simultaneous occurrence of mutation and del $) 17 \mathrm{p}($, which is associated with a poorer prognosis than the time they occur separately, leads to increased carcinogenesis. ${ }^{15,19}$ Also, Cazzola et al. demonstrated that coexistence of mutation in chromatin modifiers (e.g., TET2, DNMT3A, and ASXL1) and TP53 mutation leads to MDS progression and a poorer prognosis (Table 1). ${ }^{20}$ Therefore, it may be possible to predict MDS prognosis/progression and transformation to different types of leukemia by examining TP53 mutations and $\mathrm{CK}$ in MDS/progressive MDS to leukemia.

\section{Del (5q)}

Del $(5 q)$ involves the deletion of $q 31-q 33$ on the long arm of chromosome $5^{21}$ that is observed in $10-15 \%$ of MDS patients. ${ }^{22}$ In this regard, it has been observed that deletion in 5q32-33 region is the most common deletion in $\operatorname{del}(5 q)$. On the other hand, deletion in $5 \mathrm{q} 31$ region is accompanied by a higher risk of MDS and AML. ${ }^{22}$ Coexistence of del (5q) and a set of chromosomal abnormalities such as der (1) $\mathrm{t}(1: 2),-7,-15,-18,-19$ with TP53 mutation can lead to $\mathrm{CK} .{ }^{23,24}$ Ammatuna et al. demonstrated that MDS with single chromosomal abnormality of del (5q) has a more favorable prognosis in comparison to other chromosomal abnormalities, while del $(5 q)$ together with $\mathrm{CK}$ will have an unfavorable prognosis. ${ }^{25}$ Also, since $5 \mathrm{q}$ region harbors genes such as CSNK1A1, RPS14, EGR1, miR-145 and miR-146a, it can be stated that the absence of these genes in del $(5 q)$ can lead to selective sensitivity to lenalidomide. ${ }^{22}$ On the other hand, it has been observed that CK (including at least two abnormalities in addition to del $5 q$ ) in MDS patients is associated with a higher risk of AML progression that can affect the response to lenalidomide. For example, TP53 mutation can lead to reduced sensitivity to lenalidomide, as well as selective growth of mutant clones. ${ }^{22,24}$ Studies have shown that low risk MDS with isolated del (5q) responds well to lenalidomide treatment, but high risk MDS, which is usually associated with $\mathrm{CK}$, has a poor response to lenalidomide treatment. ${ }^{11,24,26}$ However, Lionel Ades et al. stated that a combination of chemotherapy stimulants like classical
Daunorubicin-AraC with lenalidomide can entail a better response. ${ }^{27}$ Therefore, more studies with a higher number of patients are required to assess the effect of drugs such as lenalidomide on the improvement of MDS patients with del $(5 q)$ chromosomal abnormality. In this regard, it has been observed that patients with an isolated del $(5 q)$ have a better prognosis than those with other chromosomal abnormalities; however, if this chromosomal deletion is accompanied by mutations in TP53, there will be a much poorer prognosis. ${ }^{26}$ There are a number of genes on $5 \mathrm{q}$ chromosome, including RPS14, EGR1, NPM1, APC, and CTNNA1, each of which is related to TP53 in some way or other. For example, NPM1 gene modulates the activity of TP53 and $C D K N 2 A$ tumor suppressors, and both EGR1 (a direct transcriptional regulator of tumor suppressor genes like TP53, $C D K N 1 A$, and $P T E N)$ and $A P C$ genes are involved in encoding tumor suppressor proteins (TSP) (Table 1). ${ }^{27-29}$ Therefore, further studies on the relationship between TP53 mutation and del (5q) are warranted.

\section{Double minute chromosomes and complex karyotype}

Double-minute chromosomes (DMs) are replicated DNA sequences in tumor cells that contain amplified genes such as $C$ $M Y C, M Y C N, M D M 2$, and EIF5A2, ${ }^{30-32}$ which are typically involved in increased carcinogenesis and poor prognosis of cancer. Bao et al. demonstrated that low-dose hydroxyurea (HU) treatment could reduce the frequency of DMs in human cancer cells. On the other hand, ionizing radiation can eliminate amplified genes on $\mathrm{DMs} ;{ }^{33}$ therefore, it can be stated that HU and ionizing agents play a role in the improvement of cancer prognosis. On the other hand, it has been shown that DMs are associated with the frequency of sister chromatid exchange (SCE) in cancer cells and the increased malignancy in cancer. ${ }^{34}$ In a study conducted on patients with myeloid malignancies and MDS, it was observed that all patients with $M L L$ gene amplification on their DMs were associated with CK like -6, add (8) (q24), der (10) t(10;11), (q28, q13), -11, add (12) (p13), + 13, +13, add (17) (p13), -18, -21, -22, + 1-3 mar, 0 2dmin [Cp20], del (11) (q21q23), add (17) (p13), $20.0 \sim 3 \mathrm{dmin}$ [16] / 46, idem, + mar [4]. ${ }^{35}$ On the other hand, patients with $D M s$ and CK were associated with $17 \mathrm{p} /$ TP53 deletion, so it can be stated that there is a relationship between DMs and CK with a poor prognosis (Table 1). ${ }^{35}$ Consequently, conducting further studies on the methods reducing/inhibiting DMs in cancer cells might prevent poor prognosis or MDS progression.

\section{Ring chromosome and complex karyotype}

Ring chromosome (RC) is a circular DNA molecule ${ }^{36}$ formed by merging of two broken ends of a chromosome, a broken end with the end of telomeres of a chromosome, or the two ends of telomeres of a chromosome. ${ }^{37} \mathrm{RC}$ is a rare disorder; However, in $75 \%$ of AML patients and $97 \%$ of MDS patients holder RC mutation, the CK [such as der (9p), der (12) dic (12;?19), +15, 18] have been observed. ${ }^{38,39}$ Research has shown that RC increase in MDS is associated with progression of MDS to AML. Moreover, MDS patients with $\mathrm{CK}+\mathrm{RC}+$ have shorter leukemiafree survival than those with $\mathrm{RC}+\mathrm{CK}-$. On the other hand, $\mathrm{CK}+\mathrm{RC}+\mathrm{AML}$ patients have an overall survival (OS) similar to $\mathrm{CK}+\mathrm{RC}-\mathrm{AML}$ patients, but they have a shorter OS compared to CK-RC+ patients (Table 1). ${ }^{39,40}$ 

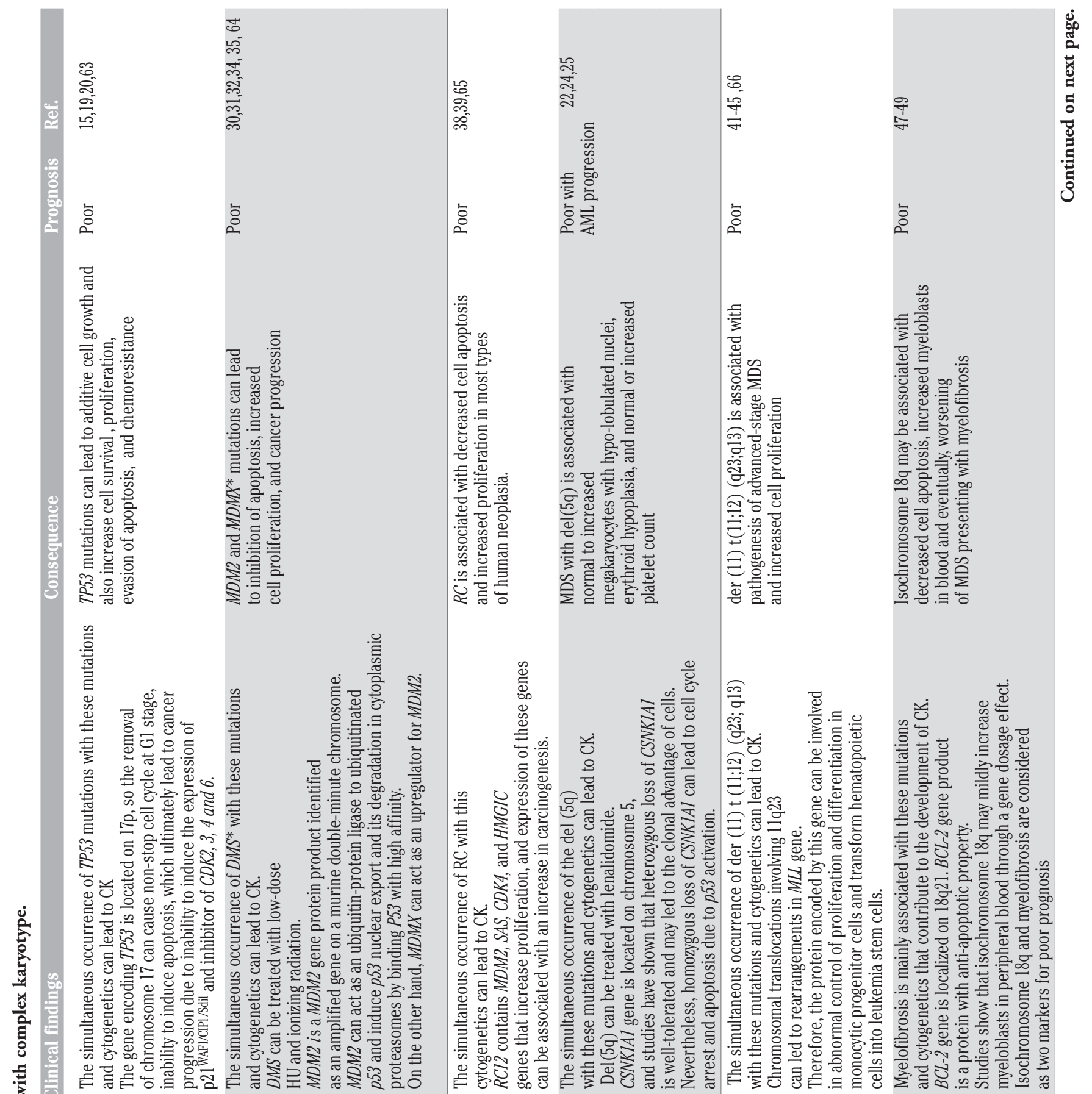

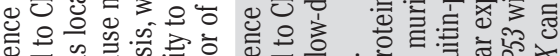

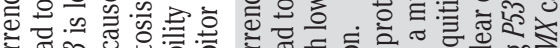

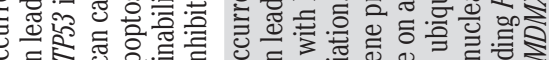

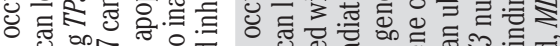

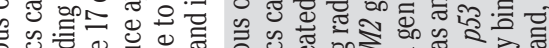

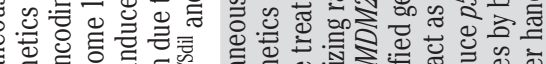
焉焉记

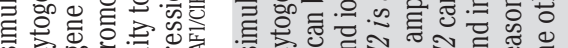

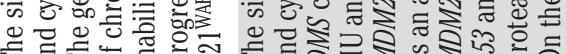

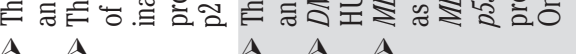

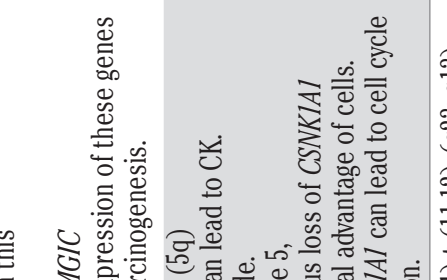

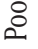

$\stackrel{\circ}{\circ}$

.

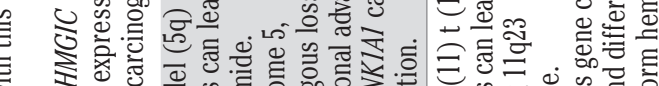

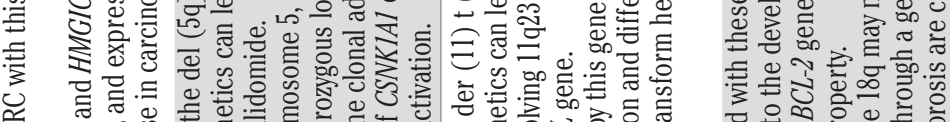
式言总

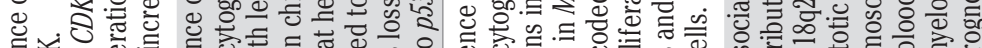

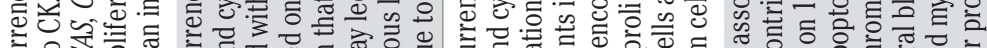

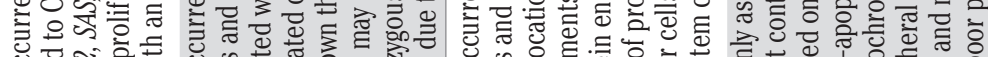

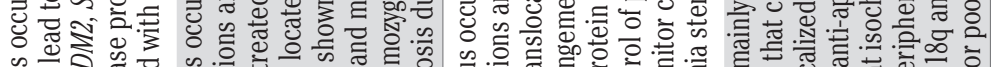

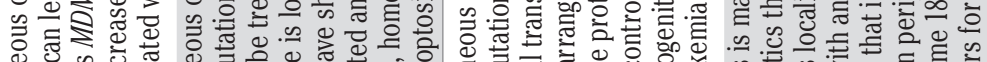
过 क

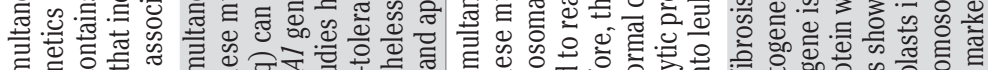

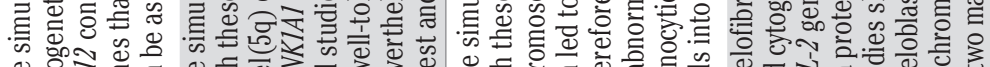

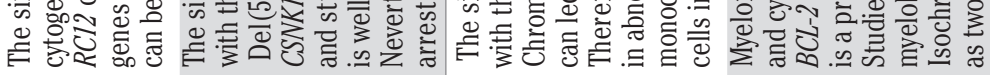
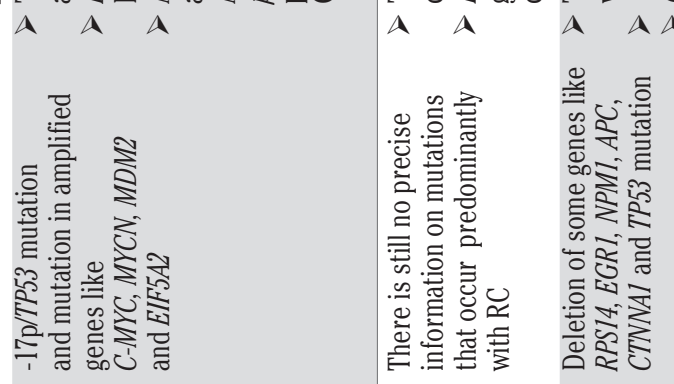

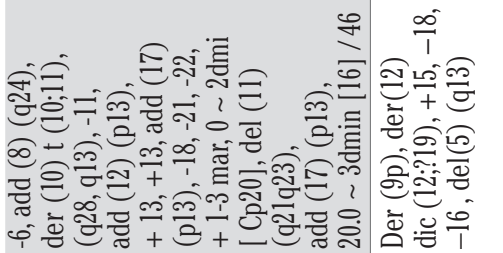

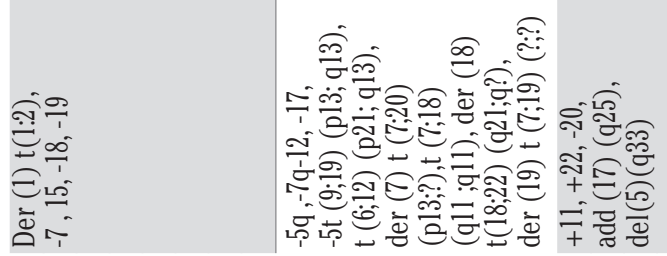




\section{Der (11) t $(11 ; 12)(q 23 ; q 13)$ and complex karyotype}

Der $(11) \mathrm{t}(11 ; 12)(\mathrm{q} 23 ; \mathrm{q} 13)$ is an unbalanced translocation (partial monosomy or trisomy) that occurs non-randomly and may be associated with the pathogenesis of advanced stage MDS. ${ }^{41,42}$ Investigations show that der $(11) \mathrm{t}(11 ; 12)(\mathrm{q} 23 ; \mathrm{q} 13)$ in refractory anemia with excess of blasts in transformation (RAEB-t), which is a type of MDS, can be associated with a series of chromosomal aberrations such as $-12,-17,-5, \mathrm{t}(9 ; 19)(\mathrm{p} 13 ; \mathrm{q} 13), \mathrm{t}(6 ; 12)$ $(\mathrm{p} 21 ; \mathrm{q} 13),{ }^{43} \operatorname{der}(7) \mathrm{t}(7 ; 20)(\mathrm{p} 13 ; ?) \mathrm{t}(7 ; 18) \quad(\mathrm{q} 11 ; \mathrm{q} 11), \operatorname{der}(19)$ $\mathrm{t}(7 ; 19)$, der(18) $\mathrm{t}(18 ; 22)$ (q21;q?), deletions of $5 \mathrm{q}$ and $7 \mathrm{q}$ and lead to CK. CK mainly occurs in advanced stage MDS and is associated with a poor prognosis (Table 1). ${ }^{41,42,44,45}$ Therefore, by conducting further studies on the relationship between der (11) $t(11 ; 12)$ (q23;q13) and advanced stage MDS, der (11) t (11;12) (q23;q13) might prove a target for advanced stage MDS therapeutic methods.

\section{Myelofibrosis and complex karyotype}

Myelofibrosis is a rare disorder associated with BM fibrosis and accumulation of immature precursors of three hematopoietic cell lines. ${ }^{46-47}$ It can be associated with MDS and a number of chromosomal abnormalities such as $-18,-20,+22,+11$, add (17) (q25), del(5)(q33), and isochromosome of long arm of chromosome 18.47-49 Elizabeth E et al. indicated that if MDS is accompanied with fibrosis and chromosomal abnormalities, the prognosis will be poorer than the case MDS is associated with chromosomal abnormalities without fibrosis (Table 1). ${ }^{50}$ Therefore, BM biopsy together with cytogenetic study is suggested in MDS patients presenting with a decrease in hematopoietic cell lineages and splenomegaly.

\section{N-RAS point mutation and complex karyotype}

$R A S$ isoforms, which include $N$-, $K$-, and $H-R A S$, are GTPases that play a role in cell growth, differentiation, migration, and apoptosis. ${ }^{51,52}$ Therefore, mutations in $R A S$ isoforms are dominant mutations in MDS and AML subtypes such as acute megakaryoblastic leukemia (AML-M7). ${ }^{53}$ Studies have shown that a point mutation in the gene encoding $N-R A S$ at codon 12 is one of the most common mutations in MDS and AML-M7, which could possibly contribute to the progression of MDS to AML-M7. ${ }^{54,55} \mathrm{~A}$ number of studies have suggested a mechanism for MDS development via uncontrolled proliferation of hematopoietic cells independent of growth factors, which is followed by mutations in $R A S$ proto-oncogene and its signaling pathway. ${ }^{56-58}$ Nevertheless, other studies indicate that compared to other mutations in $R A S$ isoforms, aspartate substitution with glycine in $N-R A S$ codon 12 is capable of maintaining $\geq 40 \%$ activity of wild type GTPases, which can be considered as another mechanism for mutation in the cell. ${ }^{55,59}$ As a result, no exact mechanism has been described for the relationship between mutation of RAS isoforms and MDS progression to AML. In this regard, during the progression of MDS to AML, N-RAS point mutation can occur together with chromosomal anomalies such as $\mathrm{t}(4 ; 11)(\mathrm{q} 21 ; \mathrm{q} 23)$, del(5) (q13q33), t (12;13) (p13;q21) [31] $/ 92, X X X X$, idem $\times 2$ [6] /46, XX, i (17) (q10) [2] /46, XX [2] to result in $\mathrm{CK} ;{ }^{60-62}$ therefore, these chromosomal abnormalities can be associated with a poor prognosis. Teresa de Souza Fernandez et al. indicated that isochromosome $17 \mathrm{q}$ and polyploidy were probably caused by genetic instability due to transformation 
of MDS into malignant leukemia (Table 1). ${ }^{62-65}$

Figures 1 and 2 show several examples of independent chromosome aberrations in CK.

\section{Discussion and Conclusions}

CK, which refers to independent chromosomal abnormalities ( $\geq 3-5$ independent chromosomal abnormalities), is among the worst risk factors of MDS patients. An increase in the number of chromosomal abnormalities in MDS has been related with poorer

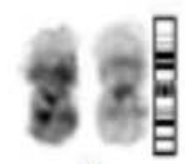

1

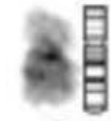

6

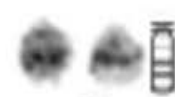

13

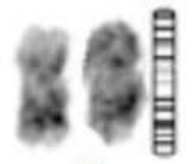

2

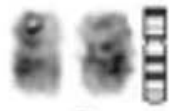

7

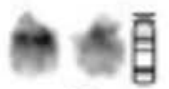

14

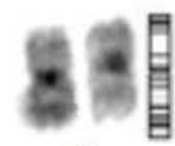

3

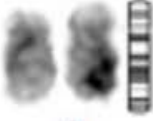

4

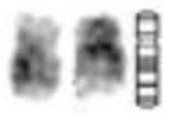

8

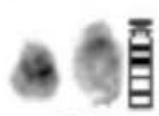

15

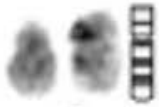

9

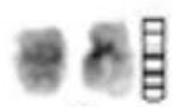

10

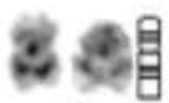

11
- - 冝

16

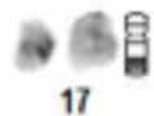

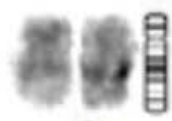

5

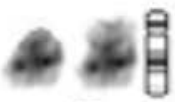

12
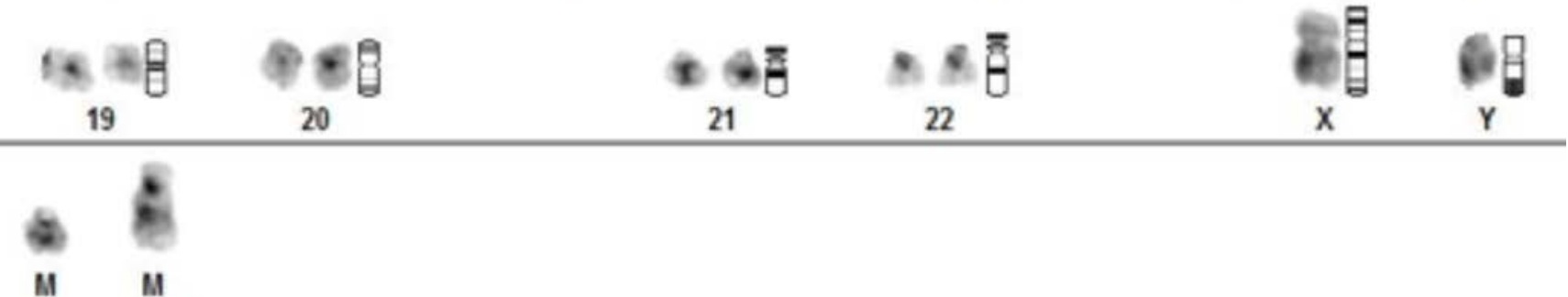

Figure 1. Examples of CK, including independent chromosome aberrations such as -6 , der (9) (12), +2 mar.

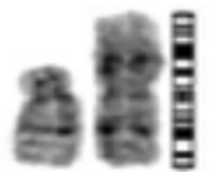

1

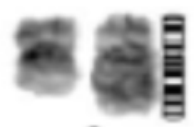

6.

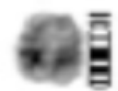

17

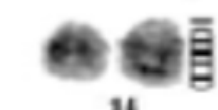

14

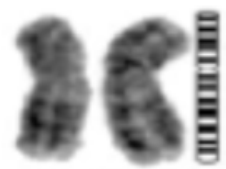

z

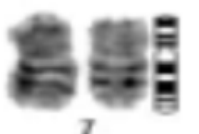

7

\section{8}

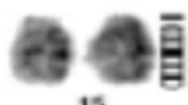

15

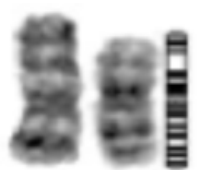

3

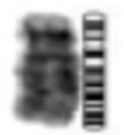

4

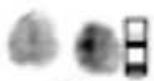

18
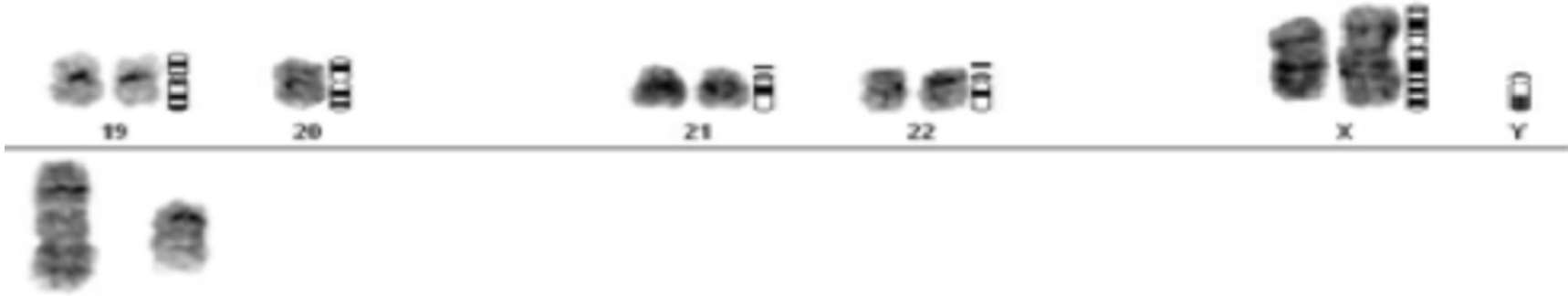

M

$\mathbf{M}$

Figure 2. Examples of CK, involving independent chromosome aberrations such as $-4,-5,-8,-10,-13,-18,-20$, der $(1)(6)$, +2 mar. 
prognosis, decreased OS, and increased progression to AML, although the prognosis of an isolated chromosomal abnormality can be different with its prognosis in CK. For example, del $(5 q)$ by itself is associated with a good prognosis and lower progression rates to AML, while when associated with other genetic abnormalities to form $\mathrm{CK}$, del $(5 \mathrm{q})$ has a poorer prognosis and higher AML progression rates. On the other hand, patients with $\mathrm{CK}$ having at least four independent chromosomal abnormalities show an increased risk of relapse. CK can also affect a number of drugs applied to treat MDS or leukemia, reducing the effectiveness of the drug in treatment of the disease. However, according to studies, it may be argued that the degree of CK interference with effectiveness of drug can be different based on the types of independent chromosomal abnormalities that form CK. Therefore, by conducting studies focusing on a series of chromosomal abnormalities involved in the formation of CK, approaches can be introduced to determine the prognosis of MDS and prevent the progression of MDS to leukemia and its relapse.

\section{References}

1. Peterson JF. The complexities of defining a complex karyotype in hematological malignancies: a need for standardization? Acta Haematologica 2017;138:65-6.

2. Campo E, Swerdlow SH, Harris NL, et al. The 2008 WHO classification of lymphoid neoplasms and beyond: evolving concepts and practical applications. Blood 2011;117:5019-32.

3. Arber DA, Orazi A, Hasserjian R, et al. The 2016 revision to the World Health Organization classification of myeloid neoplasms and acute leukemia. Blood 2016;127:2391-405.

4. Gohring G, Michalova K, Beverloo HB, et al. Complex karyotype newly defined: the strongest prognostic factor in advanced childhood myelodysplastic syndrome. Blood 2010;116:3766-9.

5. Haase D, Germing U, Schanz J, et al. New insights into the prognostic impact of the karyotype in MDS and correlation with subtypes: evidence from a core dataset of 2124 patients. Blood 2007;110:4385-95.

6. Cohen N, Trakhtenbrot L, Yukla M, et al. SKY detection of chromosome rearrangements in two cases of tMDS with a complex karyotype. Cancer Genet Cytogenet 2002;138:12832.

7. Schrock E, du Manoir S, Veldman T, et al. Multicolor spectral karyotyping of human chromosomes. Science (New York, NY) 1996;273:494-7.

8. Cogle CR, Saki N, Khodadi E, et al. Bone marrow niche in the myelodysplastic syndromes. Leuk Res 2015;39:1020-7.

9. Trost D, Hildebrandt B, Beier M, et al. Molecular cytogenetic profiling of complex karyotypes in primary myelodysplastic syndromes and acute myeloid leukemia. Cancer Genet Cytogenet 2006;165:51-63.

10. Heim S, Mitelman F. Cancer cytogenetics: chromosomal and molecular genetic aberrations of tumor cells. London: John Wiley \& Sons; 2015.

11. Malcovati L, Germing U, Kuendgen A, et al. Time-dependent prognostic scoring system for predicting survival and leukemic evolution in myelodysplastic syndromes. J Clin Oncol 2007;25:3503-10.

12. Sato N, Nakazato T, Kizaki M, et al. Transformation of myelodysplastic syndrome to acute lymphoblastic leukemia: a case report and review of the literature. Int $\mathrm{J}$ Hematol 2004;79:147-51.

13. Musilová J, Michalová K, Zemanova Z, et al. Karyotype at diagnosis, subsequent leukemic transformation and survival in myelodysplastic syndrome. Czechoslovak MDS Cooperative Group; 1995.

14. Greenberg PL, Tuechler H, Schanz J, et al. Revised international prognostic scoring system for myelodysplastic syndromes. Blood 2012;120:2454-65.

15. Rivlin N, Brosh R, Oren M, et al. Mutations in the p53 tumor suppressor gene: important milestones at the various steps of tumorigenesis. Genes \& Cancer 2011;2:466-74.

16. Wang W, Routbort MJ, Tang Z, et al. Characterization of TP 53 mutations in low $\square$ grade myelodysplastic syndromes and myelodysplastic syndromes with a non-complex karyotype. Eur J Haematol 2017;99:536-43.

17. Kulasekararaj AG, Smith AE, Mian SA, et al. TP53 mutations in myelodysplastic syndrome are strongly correlated with aberrations of chromosome 5, and correlate with adverse prognosis. Br J Haematol 2013;160:660-72.

18. Pedersen-Bjergaard J, Andersen MK, Christiansen DH, et al. Genetic pathways in therapy-related myelodysplasia and acute myeloid leukemia. Blood 2002;99:1909-12.

19. Stengel A, Kern W, Haferlach T, et al. The impact of TP53 mutations and TP53 deletions on survival varies between AML, ALL, MDS and CLL: an analysis of 3307 cases. Leukemia 2017;31:705-11.

20. Cazzola M, Della Porta MG, Malcovati L. The genetic basis of myelodysplasia and its clinical relevance. Blood 2013;122:4021-34.

21. Giagounidis AA, Germing U, Wainscoat JS, et al. The 5q-syndrome. Hematology (Amsterdam, Netherlands) 2004;9:271-7.

22. Hosono N, Makishima H, Mahfouz R, et al. Recurrent genetic defects on chromosome $5 \mathrm{q}$ in myeloid neoplasms. Oncotarget 2017;8:6483-95.

23. Giagounidis AAN, Haase S, Heinsch M, et al. Lenalidomide in the context of complex karyotype or interrupted treatment: case reviews of del(5q)MDS patients with unexpected responses. Ann Hematol 2007;86:133-7.

24. List A, Ebert BL, Fenaux P. A decade of progress in myelodysplastic syndrome with chromosome $5 \mathrm{q}$ deletion. Leukemia 2018;32:1493-9.

25. Ammatuna E, Panetta P, Agirre X, et al. NPM1 gene deletions in myelodysplastic syndromes with 5q- and complex karyotype. Haematologica 2011;96:784-5.

26. Ades L, Boehrer S, Prebet T, et al. Efficacy and safety of lenalidomide in intermediate-2 or high-risk myelodysplastic syndromes with $5 \mathrm{q}$ deletion: results of a phase 2 study. Blood 2009;113:3947-52.

27. Ades L, Prebet T, Stamatoullas A, et al. Lenalidomide combined with intensive chemotherapy in acute myeloid leukemia and higher-risk myelodysplastic syndrome with $5 \mathrm{q}$ deletion. Results of a phase II study by the Groupe Francophone Des Myélodysplasies. Haematologica 2017;102:728-35.

28. Baron V, Adamson ED, Calogero A, et al. The transcription factor Egr1 is a direct regulator of multiple tumor suppressors including TGFbeta1, PTEN, p53, and fibronectin. Cancer Gene Ther 2006;13:115-24.

29. Mollgard L, Saft L, Treppendahl MB, et al. Clinical effect of increasing doses of lenalidomide in high-risk myelodysplastic syndrome and acute myeloid leukemia with chromosome 5 abnormalities. Haematologica 2011;96:963-71.

30. Alitalo K, Schwab M, Lin CC, et al. Homogeneously staining chromosomal regions contain amplified copies of an abundantly expressed cellular oncogene (c-myc) in malignant neuroendocrine cells from a human colon carcinoma. Proc Natl Acad Sci 1983;80:1707. 
31. VanDevanter DR, Piaskowski VD, Casper JT, et al. Ability of circular extrachromosomal DNA molecules to carry amplified MYCN proto-oncogenes in human neuroblastomas in vivo. $\mathrm{J}$ Natl Cancer Inst 1990;82:1815-21.

32. Fakharzadeh SS, Rosenblum-Vos L, Murphy M, et al. Structure and organization of amplified DNA on double minutes containing the mdm2 oncogene. Genomics 1993;15:28390.

33. Bao Y, Liu J, You J, et al. Met promotes the formation of double minute chromosomes induced by Sei-1 in NIH-3T3 murine fibroblasts. Oncotarget 2016;7:56664-75.

34. Xu J, Liu P, Meng X, et al. Association between sister chromatid exchange and double minute chromosomes in human tumor cells. Mol Cytogenet 2015;8:91.

35. Huh YO, Tang G, Talwalkar SS, et al. Double minute chromosomes in acute myeloid leukemia, myelodysplastic syndromes, and chronic myelomonocytic leukemia are associated with micronuclei, MYC or MLL amplification, and complex karyotype. Cancer Genet 2016;209:313-20.

36. Habib AGK, Sugiura K, Ueno M. Chromosome passenger complex is required for the survival of cells with ring chromosomes in fission yeast. PLoS One 2018;13:e0190523.

37. Guilherme RS, Ayres Meloni VF, Kim CA, et al. Mechanisms of ring chromosome formation, ring instability and clinical consequences. BMC Med Genet 2011;12:171.

38. Kim T, Bershteyn M, Wynshaw-Boris A. Chromosome therapy. Correction of large chromosomal aberrations by inducing ring chromosomes in induced pluripotent stem cells (iPSCs). Nucleus (Austin, Tex) 2014;5:391-5.

39. Rosenbaum MW, Pozdnyakova O, Geyer JT, et al. Ring chromosome in myeloid neoplasms is associated with complex karyotype and disease progression. Human Pathol 2017;68:406.

40. Ganguly B, Dolai T, De R, et al. Spectrum of complex chromosomal aberrations in a myelodysplastic syndrome and a brief review. J Cancer Res Ther 2016;12:1203-6.

41. Fenaux P. Chromosome and molecular abnormalities in myelodysplastic syndromes. Int J Hematol 2001;73:429-37.

42. Yamamoto K, Hato A, Minagawa K, et al. Unbalanced translocation der (11) t $(11 ; 12)(\mathrm{q} 23 ; \mathrm{q} 13)$ : a new recurrent cytogenetic aberration in myelodysplastic syndrome with a complex karyotype. Cancer Genet Cytogenet 2004;155:67-73.

43. Michels SD, Saumur J, Arthur DC, et al. Refractory anemia with excess of blasts in transformation hematologic and clinical study of 52 patients. Cancer 1989;64:2340-6.

44. Fenaux P, Morel P, Lai J. Cytogenetics of myelodysplastic syndromes. Semin Hematol 1996;33:127-38.

45. Mecucci C. Molecular features of primary MDS with cytogenetic changes. Leukemia research 1998; 22: 293-302.

46. Bearman RM, Pangalis GA, Rappaport H. Acute ("malignant") myelosclerosis. Cancer 1979;43:279-93.

47. Sultan C, Imbert M, Jouault H, Scoazec JY. Myelodysplastic syndromes. Acta Haetmatol 1987;1:91-3.

48. Imbert M, Nguyen D, Sultan C. Myelodysplastic syndromes (MDS) and acute myeloid leukemias (AML) with myelofibrosis. Leuk Res 1992;16:51-4.

49. Xue Y, Cao Y, Gao Y, et al. An isochromosome of the long arm of chromosome 18 in a patient with myelodysplastic syndrome with myelofibrosis. Cancer Genet Cytogenet 1995;79:149-52.

50. Allen EF, Lunde JH, McNally R, et al. A case of acute myelofi- brosis with complex karyotypic changes: a type of myelodysplastic syndrome. Cancer Genet Cytogenet 1996;90:24-8.

51. Cox AD, Der CJ. Ras history: the saga continues. Small GTPases 2010;1:2-27.

52. Bertacchini J, Ketabchi N, Mediani L, et al. Inhibition of Rasmediated signaling pathways in CML stem cells. Cell Oncol (Dordrecht) 2015;38:407-18.

53. Vasioukhin V, Anker P, Maurice P, et al. Point mutations of the N-ras gene in the blood plasma DNA of patients with myelodysplastic syndrome or acute myelogenous leukaemia. Br J Haematol 1994;86:774-9.

54. de Souza Fernandez T, Menezes de Souza J, Macedo Silva ML, et al. Correlation of N-ras point mutations with specific chromosomal abnormalities in primary myelodysplastic syndrome. Leuk Res 1998;22:125-34.

55. Nakagawa T, Saitoh S, Imoto S, et al. Multiple point mutation of N-ras and K-ras oncogenes in myelodysplastic syndrome and acute myelogenous leukemia. Oncol 1992;49:114-22.

56. Bos JL. ras oncogenes in human cancer: a review. Cancer Res 1989;49:4682-9.

57. Downward J. Targeting RAS signalling pathways in cancer therapy. Nature Rev Cancer 2003;3:11-22.

58. Badar T, Patel KP, Thompson PA, et al. Detectable FLT3-ITD or RAS mutation at the time of transformation from MDS to AML predicts for very poor outcomes. Leuk Res 2015;39:1367-74.

59. Chin YM1, Bosco JJ, Koh CL. Analysis of ras gene mutations in acute myeloid leukemia by the polymerase chain reaction and oligonucleotide probes. Singapore Med J 1992;33(1):4850 .

60. Ohyashiki K, Yoshida MA, Ohyashiki J, et al. Involvement of chromosomes 4, 11, and 17 in a case of myelodysplastic syndrome. Cancer Genet Cytogenet 1985;18:265-73.

61. Suciu S, Kuse R, Weh HJ, et al. Results of chromosome studies and their relation to morphology, course, and prognosis in 120 patients with de novo myelodysplastic syndrome. Cancer Genet Cytogenet 1990;44:15-26.

62. de Souza Fernandez T, Ornellas MH, de Carvalho LO, et al. Complex karyotype and N-RAS point mutation in a case of acute megakaryoblastic leukemia (M7) following a myelodysplastic syndrome. Cancer Genet Cytogenet 2000;117:104-7.

63. Shaw PH. The role of p53 in cell cycle regulation. Pathol Res Pract 1996;192:669-75.

64. Neochoritis C, Estrada-Ortiz N, Khoury K, et al. Chapter twelve - p53-MDM2 and MDMX antagonists. In: Desai MC, eds. Annual reports in medicinal chemistry. Academic Press; 2014. pp 167-87.

65. Gisselsson D, Hoglund M, Mertens F, et al. The structure and dynamics of ring chromosomes in human neoplastic and nonneoplastic cells. Human Genet 1999;104:315-25.

66. Munoz L, Nomdedeu JF, Villamor N, et al. Acute myeloid leukemia with MLL rearrangements: clinicobiological features, prognostic impact and value of flow cytometry in the detection of residual leukemic cells. Leukemia 2003;17:76-82.

67. Zenonos K, Kyprianou K. RAS signaling pathways, mutations and their role in colorectal cancer. World J Gastrointest Oncol 2013;5:97-101.

68. Fearon ER. Molecular genetics of colorectal cancer. Ann Rev Pathol 2011;6:479-507. 